\title{
Intrasellar Chondroma
}

\author{
Hirofumi Munemitsu****, Masayuki Matsuda*, Osamu Hiral, \\ Taro FukUmitsu** and Junichiro KAWAMURA*** \\ Department of Neurosurgery, Shizuoka Rosai Hospital, Hamamatsu 430 \\ *Department of Neurosurgery, Shiga University of Medical Science \\ **Department of Neurosurgery, Kobe Central Municipal Hospital \\ ${ }^{* * *}$ Department of Neurology, Tenri Hospital
}

\begin{abstract}
Summary
Chondromas rarely develop in the cranial fossa. Among 150 cases of intracranial chondromas reported, only ten arose within the sella turcica. A case of a 50-year-old man with intrasellar chondroma is presented. He had a chiasmal syndrome which lead us to the preoperative diagnosis of pituitary adenoma. It is very hard to differentiate an intrasellar chondroma firom a pituitary adenoma or craniopharyngioma before histological examination.

Computed tomography scan showed that the density of intrasellar chondroma is slightly lower than that of pituitary adenoma.
\end{abstract}

Key words: Chiasmal syndrome, chondroma, computed tomography, skull neoplasm

\section{Introduction}

Since the first report of an intracranial chondroma by Hirschfeld in $1851,{ }^{6}$ about 150 cases have been reported. Intracranial chondromas account for $0.1 \sim 0.2 \%$ of all intracranial tumors. Chondromas originating in the sella turcica are extremely rare. To our knowledge, there have been only ten cases of intrasellar chondroma in the literature since the first case was reported by van Duyse in $1937 .^{13 \text { ) }}$

\section{Case Report}

A 50-year-old man was admitted with complaints of headaches and double vision in right lateral gaze of one-month duration and with a one-year history of decreased libido. Neurological findings on admission were right abducens palsy, horizontal nystagmus in the right and left lateral gazes and nasal inferior quadrantanopsia of the left eye (Fig. 1). Visual acuity and optic fundi were normal.

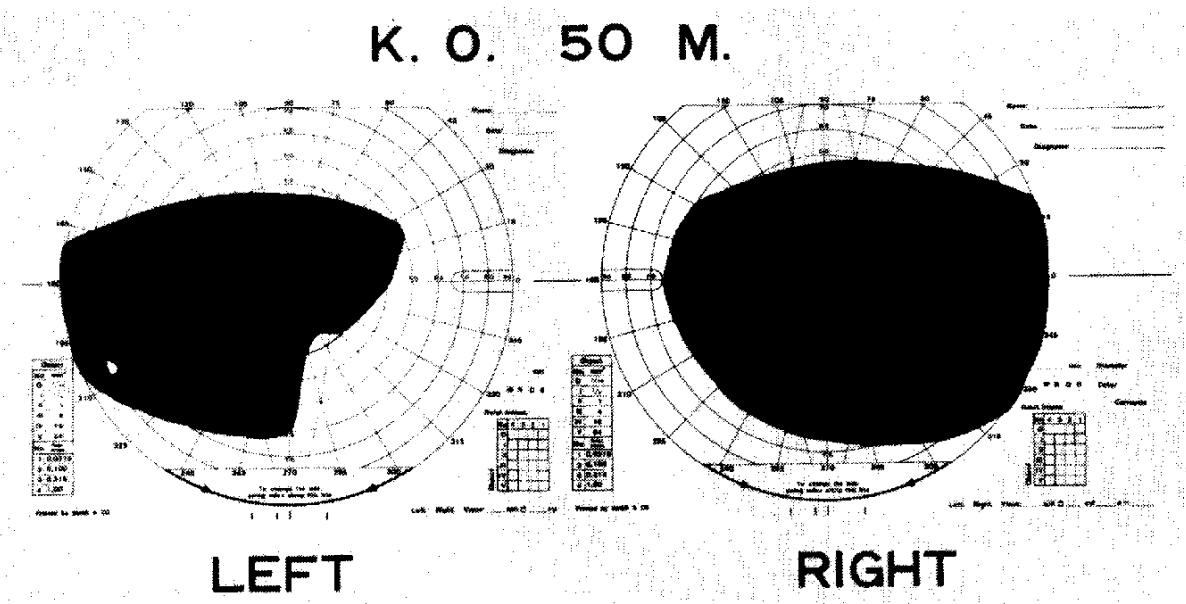

Fig. 1 Perimetry. Left nasal inferior quadrantanopsia.

****Present address: Department of Neurosurgery, Kyoto University, Medical School 
Plain skull films showed an irregularly enlarged sella turcica and calcification in the suprasellar region (Fig. 2). Right retrograde brachial angiograms demonstrated slight elevation of the proximal portion of the anterior cerebral artery and lateral displacement of the cavernous portion of the right internal carotid artery (Fig. 3A and B). No abnormalities were found on the other side. Computed tomography revealed a mass with high density (Hounsfield units: $30 \sim 95$ ) in the sellar region and a tiny calcification within the mass. The mass extended into the suprasellar and right parasellar regions, and was moderately enhanced after intravenous infusion of contrast material (Hounsfield units: 55 95) (Fig. 4A and B). The radioisotope brain scintigram was negative. The pneumoencephalogram revealed a mass with smooth contours in the chiasmatic and interpeduncular cisterns (Fig. 5). The electroencephalogram showed no abnormalities. Endocrinological examinations indicated a partial dysfunction of the anterior lobe of the pituitary gland. The glucose tolerance test was of the borderline type (Fig. 6). Preoperative diagnosis was pituitary adenoma. In the operation, an encapsulated tumor was found in the sellar region. The mass extended upwards into the right parasellar region. The surface was smooth, but the capsule was hypervascular, and the contents gelatinous. Subtotal removal of the mass was performed intracapsularly. A small hard mass was observed in the superior posterior portion of the tumor, which was thought to be a compressed pituitary gland. After the

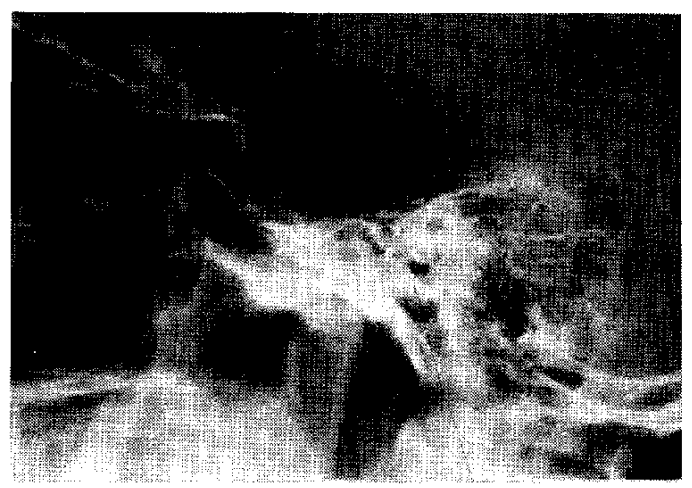

Fig. 2 Plain skull film (lateral view). Enlargement and destruction of the sella turcica, and mild suprasellar calcification.

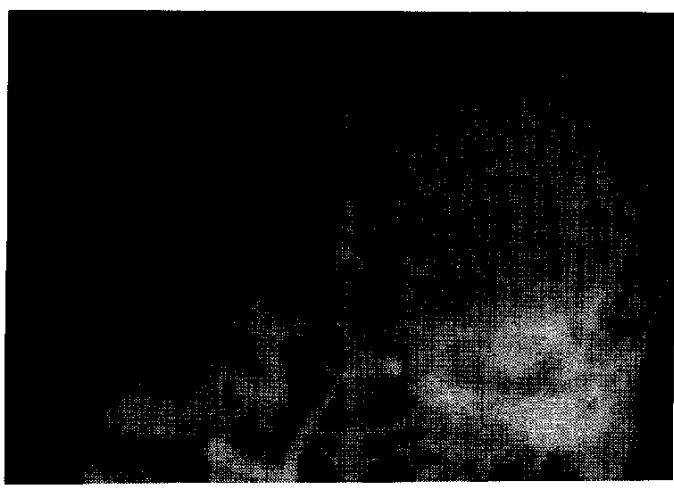

A

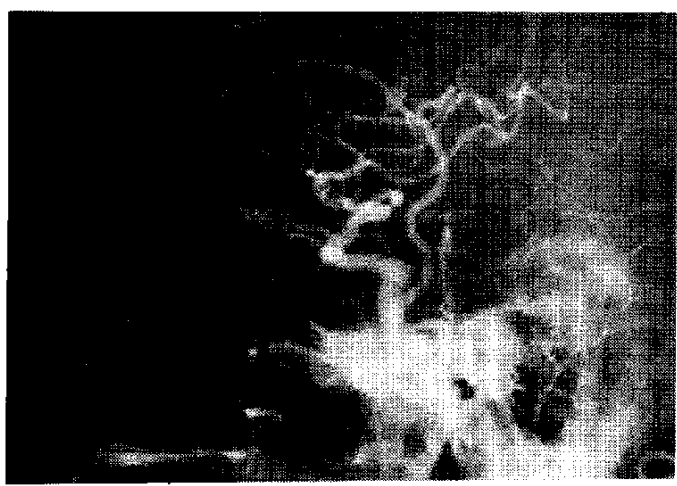

B

Fig. 3 A and B: Right retrograde brachial angiogram. Slight elevation of the proximal portion of the anterior cerebral artery and lateral displacement of the cavernous portion of the right internal carotid artery.

operation, the abducens palsy and diplopia became worse, but they disappeared 10 days later. The visual field defect was improved. Diabetes inspidus which developed two weeks after the operation was controled by medication.

Irradiation of a total dose of 5,000 rads divided into 25 fractions was administered to the residual tumor because it was thought to be a pituitary adenoma. A histological report a month after the operation revealed that it was a chondroma (Fig. 7).

Computed tomography after the irradiation therapy showed no abnormal density around the sellar region on plain scans, but a small enhanced lesion was observed in the same region in a contrast study. The patient has been doing well without neurological deficits for the past 25 months after discharge. 


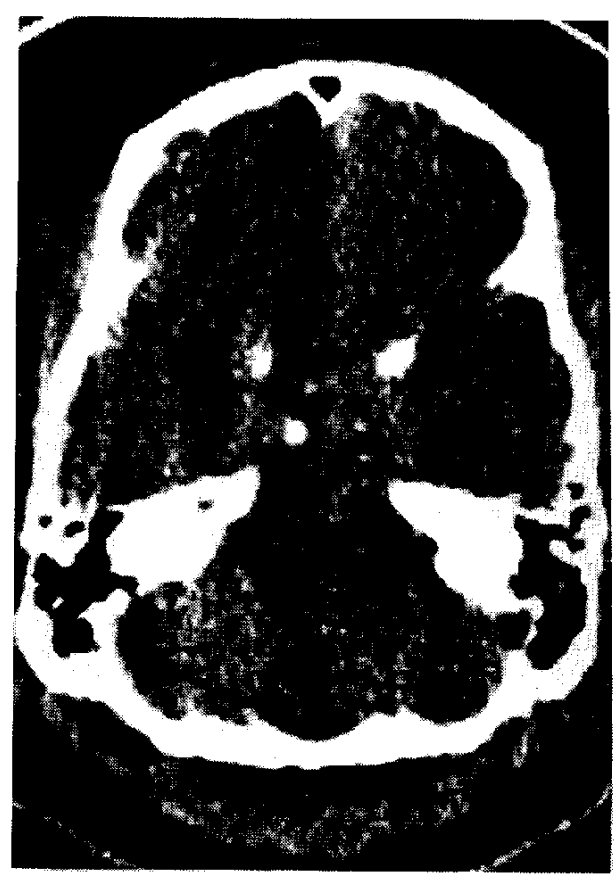

A

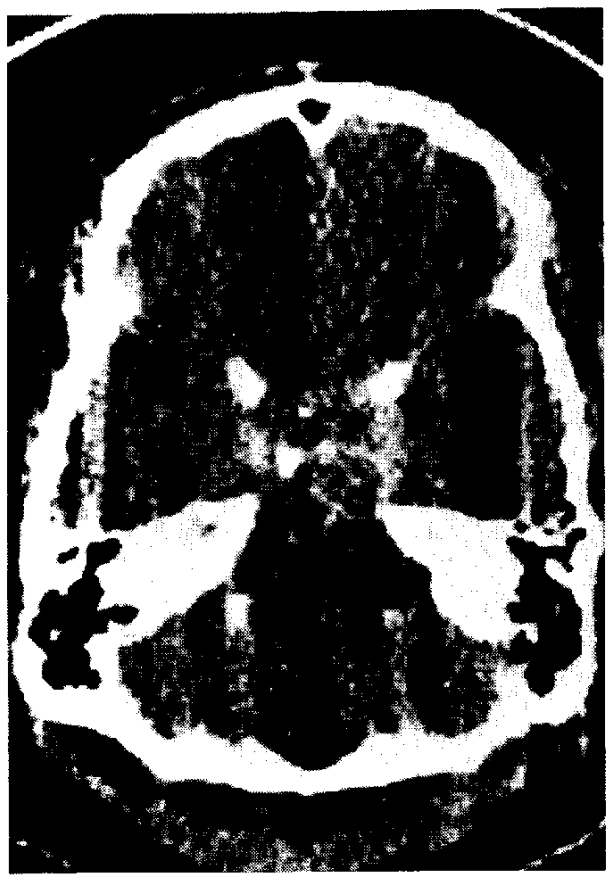

B

Fig. 4 A and B: Computed tomography (pre- and post-contrast study). High density mass in the suprasellar and right parasellar regions including calcification density on plain CT scan, and moderate enhancement of the mass in post-contrast study.

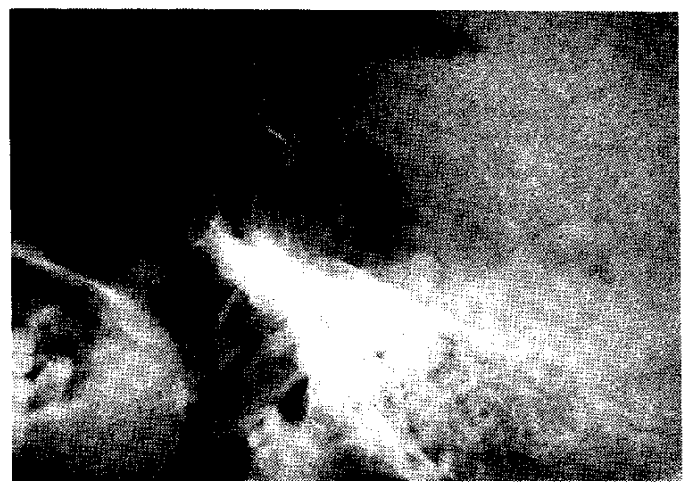

Fig. 5 Pneumoencephalogram. Suprasellar mass lesion in the chiasmatic and the interpeduncular cisterns.

Fig. 6 Endocrinological examinations. Hypofunction of TSH and HGH secretion is observed. Secretion of LH and FSH is within normal limits. Glucose tolerance test is of the borderline type.

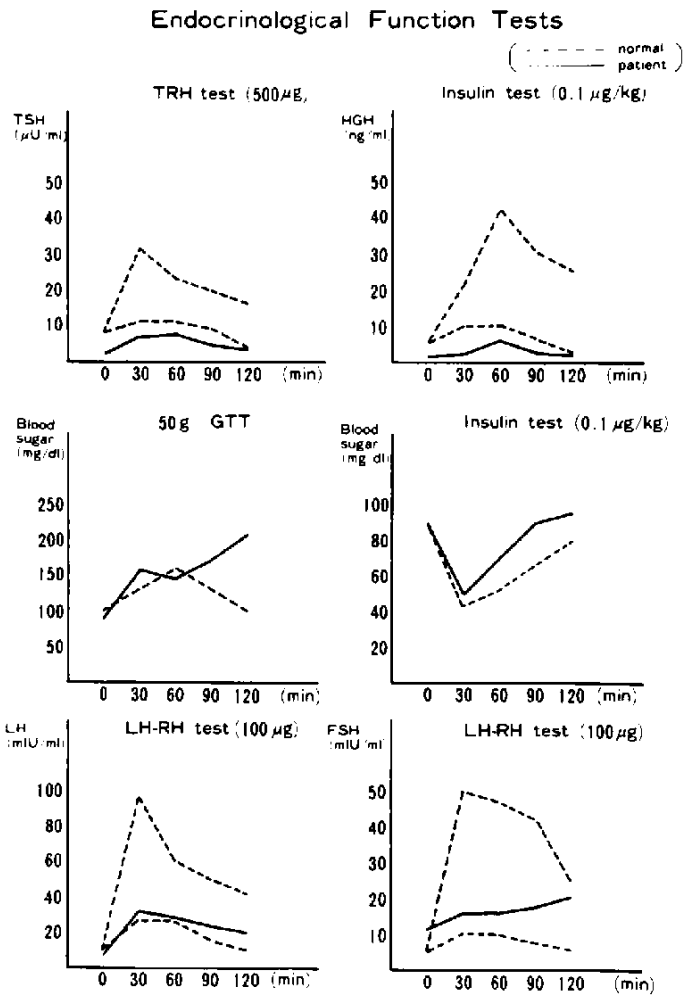




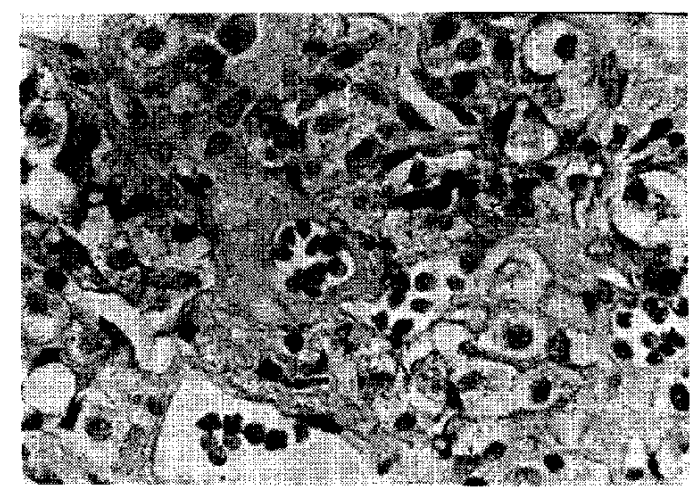

Fig. 7 Histology (Hematoxylin-Eosin staining, $\times 400$ ). Multiple cartilagenous nodules with hypervascular fibrous connective tissues are scattered.

\section{Discussion}

The eleven cases of intrasellar chondroma including the present case included five males and six females and their ages ranged from 16 to 60 years old (Table 1). The signs and symptoms reported in these cases were visual field defect, cranial nerve palsies and hypopituitarism (chiasmal syndrome), which are commonly observed in cases of pituitary adenoma. There was nothing pathognomonic for the intrasellar chondroma. It was not until the histological study was performed that correct diagnosis was made in all of the previously reported cases as well as in the present case. The differential diagnosis of intrasellar chondroma from pituitary adenoma or craniopharyngioma is difficult roentogenographically. Calcification is of no use in the differentiation. ${ }^{7,8)}$ The shape of the destroyed sella turcica might be of some help. It is irregularly shaped in intrasellar chondromas, and it is peculiarly shaped in pituitary adenomas or craniopharyngiomas. Angiograms are of no value in the diagnosis of intrasellar chondromas. Reports on CT findings of this tumor are scarce. ${ }^{12)}$ In our case, the density of the tumor was slightly lower than that of pituitary adenoma on plain CT scans, and the mass was moderately enhanced in a contrast study. During the operation, it is also very hard to tell intrasellar chondromas from pituitary adenomas, but the former seem to have a firm capsule. In 1963, Marcove and Francis ${ }^{9)}$ pointed out the acceleration of glucose degeneration in patients with chondroma. The glucose tolerance test in our case was of the borderline type.

Irradiation is reported to be ineffective, and some authors even state that it is contraindicated. ${ }^{7,8)}$ Irradiation which was given in the present case due to an erroneous diagnosis of pituitary adenoma was also not effective. Surgical removal is the only treatment for an intrasellar chondroma.

Concerning pathogenesis, it is reported that an intracranial chondroma develops from the residual fetal cartilagenous tissue. ${ }^{8)}$ The origin of intrasellar chondromas was discussed only by de Divitiis et al. in $1979^{3}$ ) who stated that it should be the same as that of intracranial chondromas in general.

The life expectancy of skull base chondroma cases is said to be good even without operations, because they are histologically benign and slow in growing. For the same reason, an intrasellar chondroma has a relatively good clinical prognosis if the accompanying hypopituitarism is well controlled.

\section{References}

1) Asenjo, A. and Chirorino, R.: Mixochondroma endocraneano (Estudio anato-clinico de dos casos). Rev Esp Otoneurooftal 15: 15-21, 1956.

2) David, M. and Constans, J. P.: Les chon dromes intracrâniens. Sem Hôp Paris 33/19: 1195-1214, 1957.

3) de Divitiis, E., Spaziante, R., Cirillo, S., Stella, L. and Donzelli, R.: Primary sellar chondromas. Surg Neurol 11: 229-232, 1979.

4) Falconer, M. A., Bailey, I. C. and Duchen, L. W.: Surgical treatment of chordoma and chondroma of the skull base. $J$ Neurosurg 29: 261-275, 1968.

5) Hardy, J., Bertrand, C., Maltais, R., Robert, F. and Thierry, A.: Volumineux chondrosarcome calcifié de la région sellaire (Exérèse trans-sphénoïdale sous contrôle radioscopique télévisé). Neurochirurgie 12: 491-502, 1966.

6) Hirschfeld, L.: Sur une tumor cartilagineuse de la base du crâne (Enchondrome). $C R$ Séan Mem Soc Biol 3: 94-96, 1851.

7) Kingler, M.: Über Knorpelgeschwulste der schödelbasis mit intracranieller Ausdehnung. Acta Neurochir 1: 337-380, 1951.

8) List, C. F.: Osteochondroma arising from the base of the skull. Surg Gynecol Obstet 76: $480-492,1943$. 
Table 1 Reported cases of intrasellar chondroma

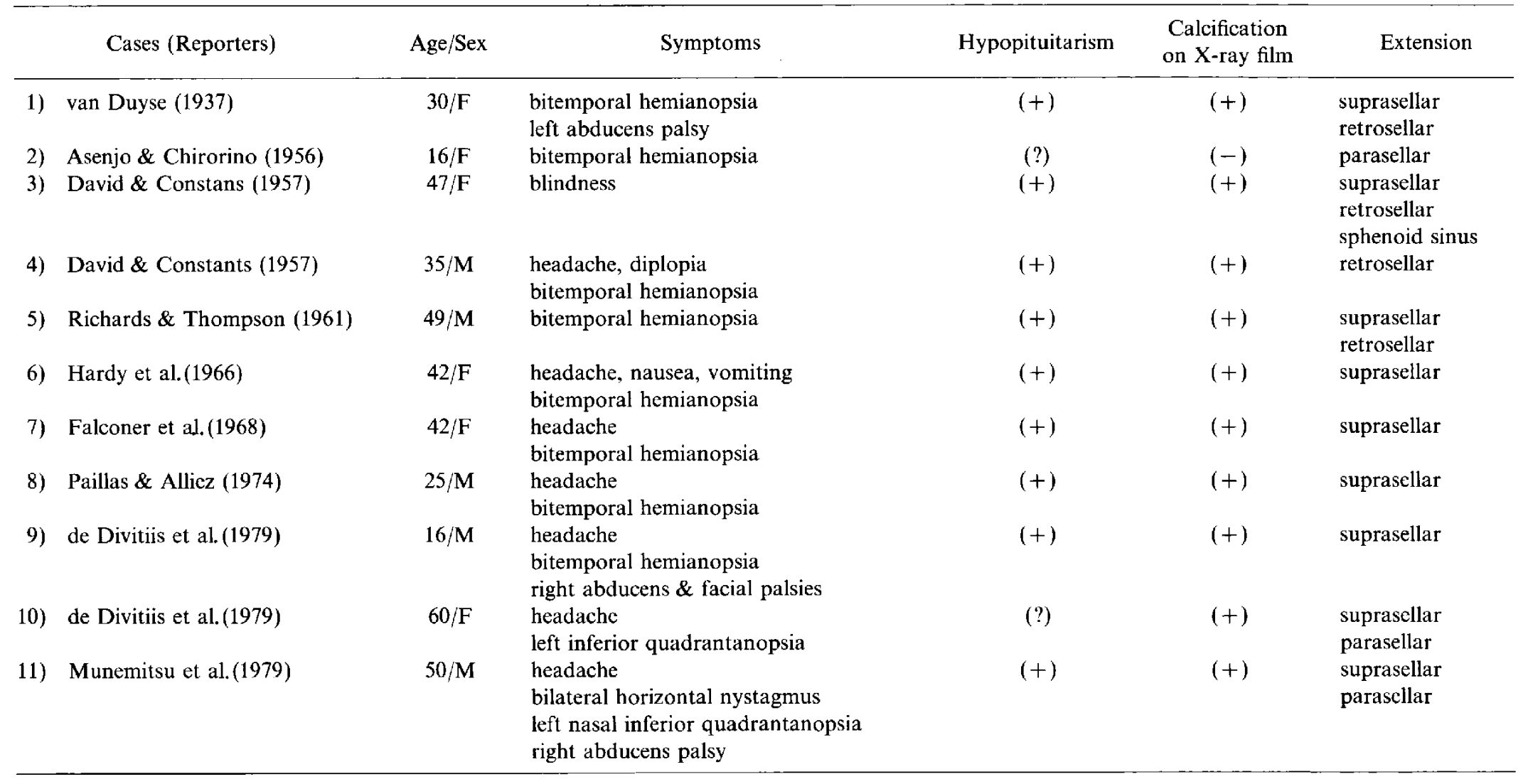


9) Marcove, R. C. and Francis, C.: Chondrosarcoma and altered carbohydrate metabolism. N Engl J Med 268: 1399-1400, 1963.

10) Paillas, J. E. and Alliez, B.: Intrasellar chondroma. Neurochirurgia 17: 136-140, 1974.

11) Richards, W, W. and Thompson, M. C.: Suprasellar osteochondroma with chiasmal syndrome. Arch Ophthalmol 65: 437-441,
1961.

12) Sarwar, M., Swischuk, L. E. and Schechter, M. M.: Intracranial chondromas. $A m J$ Roentgenol 127: 973-977, 1976.

13) van Duyse, M.: A propos d'un cas de syndrome chiasmatique et hypophysaire (Myxochondrome résultant de la métaplasie d'un crano-pharyngiome). Bull Soc Belge Ophthalmol 75: 70-77, 1937. 